\title{
A magia da cor: a química de um fogo-de-artifício*
}

$\mathrm{O}$ tradicional fogo-de-artifício é uma das mais espectaculares experiências de química, que todos conhecemos e admiramos. A história da química está ligada à história destas demonstraçōes espectaculares e poderosas, aos alquimistas e às suas "artes mágicas", e às suas demonstraçôes experimentais nas cortes reais. A grandes professores como Justus von Leibig, Michael Faraday e Georg Lichtenberg, entre outros, se deve muito desta "química do espectáculo".

Foram grandes vultos da Química quem conduziu o fogo-de-artificio à sua mais perigosa, mas também mais brilhante forma. Quando Antoine Laurent de Lavoisier (1743-1794) estabeleceu a sua teoria de que os ácidos continham oxigénio, nunca terá imaginado que esta ideia conduziria a um avanço espectacular nos fogos-de-artificio. Claude Louis Berthollet (1748-1822), contemporâneo e amigo de Lavoisier, enveredou na procura do oxigénio nos ácidos. Não o encontrou em todos, mas devido a essa busca descobriu novos ácidos contendo oxigénio e a ele se deve a preparação de uma substância perigosa, o clorato de potássio. Berthollet cedo descobriu que esta substância quando aquecida libertava, num curto espaço de tempo, todo o oxigénio que continha, e que durante essa conversāo se atingiam temperaturas extremamente elevadas. Lavoisier pensou imediatamente na possibilidade de misturar o clorato na pólvora usada pela armada francesa. Por esse motivo pediu que se preparasse uma grande quantidade desta substância no "Moinho de Pólvora" Real de Essones, o que infelizmente condu- ziu a uma detonação acidental que provocou vários mortos, enquanto Lavoisier e Berthollet se tinham ausentado para um pequeno passeio. Este acidente não impediu que o clorato de potássio continuasse a ser utilizado e que posteriormente levasse à descoberta de outras substâncias ainda mais reactivas. A elevada temperatura de combustão do clorato de potássio depressa se popularizou nas oficinas de fogo-de-artifício, especialmente na Ásia, onde desde esse momento a utilização de misturas de clorato e enxofre puros assegurou um máximo de brilho nas cores dos fogos, mas também um enorme aumento nas perdas humanas entre fabricantes e utilizadores. Na UE, o fabrico de fogo-de-artifício baseado em misturas de enxofre-clorato é proibido.

Mas a que se deve a cor? Os tons de laranja dos primeiros fogos-de-artificio são largamente produzidos por radiação do corpo negro (brilho de partículas sólidas muito quentes). Os verdes e os vermelhos são devidos à emissão espectral de átomos excitados na fase gasosa. A utilização de magnésio (1860) e alumínio (1888), metais de combustão fácil, veio aumentar o brilho dos fogos. A mistura de aparas de titânio levou a uma maior duração dos efeitos.[1]

Ainda que actualmente se obtenham cores brilhantes com maior segurança, as novas geraçōes de cores de fogos-de-artificio funcionam segundo os mesmos principios do fogo-de-artificio tradicionais.[2]

\section{Interesse da Actividade}

As cores emitidas por um átomo dependem de como os seus electrōes estāo distribuidos, da sua estrutura electrónica. Os testes de chama sẫo dos mais antigos métodos de identificação de um elemento. 0 cloreto de sódio, um composto utilizado no dia-a-dia, pode ser dado como exemplo. Investigando as cores que os átomos emitem é possível determinar a sua estrutura interna, sendo este conhecimento de crucial importância para compreender a tabela periódica, as propriedades dos elementos, os compostos que eles formam e as reacçőes em que participam, ou até as cores do fogode-artifício.[3] 0 modelo atómico, que presentemente utilizamos, teve a sua

origem na análise da luz emitida pelos átomos; os espectros de risca de um átomo sâo bem diferentes do padrăo continuo obtido quando se faz passar a luz branca do sol através de um prisma. Por este motivo esta actividade pode ser enquadrada tanto a um nivel elementar de estudo do átomo e da sua estrutura electrónica como para a introduzir conceitos de mecânica quântica, e algumas das perguntas e respostas luminosas que ajudaram grandes cientistas a aceitar o modelo quântico, ainda que a contragosto! Para além disso, são um belíssimo exemplo de Química descritiva e como tal poderão ser utilizados em cadeiras de Quimica Geral ou Inorgânica.

\section{Acerca da Actividade}

Esta actividade pode ser desenvolvida numa hotte, num laboratório de química ou, numa sala grande com boa ventilaçăo, desde que se tomem precauçōes de segurança e se ajustem as quantidades à dimensão da sala, pois ocorre libertação de fumo em grande quantidade. Devido à perigosidade do clorato de potássio o professor deverá prestar especial atenção à fase da mistura com o açúcar-nitrato. A mistura dos vários compostos não deverá nunca ser moida em almofariz! É perigoso e explosivo! Compostos orgânicos podem reagir de forma explosiva com o $\mathrm{KClO}_{3}$. [5] Utilizar sempre óculos de protecçẫo e luvas.

Durante a reacção, o clorato de potássio, assim como os nitratos, são reduzidos e o açúcar é oxidado a vapor de água e dióxido de carbono:

$$
4 \mathrm{KClO}_{3}+\mathrm{C}_{6} \mathrm{H}_{12} \mathrm{O}_{6} \rightarrow 6 \mathrm{CO}_{2}+6 \mathrm{H}_{2} \mathrm{O}+4 \mathrm{KCl}
$$

$$
12 \mathrm{NaNO}_{3}+\mathrm{C}_{6} \mathrm{H}_{12} \mathrm{O}_{6} \rightarrow 6 \mathrm{CO}_{2}+6 \mathrm{H}_{2} \mathrm{O}+12 \mathrm{NaNO}_{2}
$$

e assim sucessivamente para os outros nitratos. Posteriormente, e devido às elevadas temperaturas, formar-se-ão, a partir dos seus sais, os átomos metálicos, que por sua vez e ainda devido às temperaturas elevadas, darão origem a átomos excitados; estes átomos libertando-se da energia em excesso por emissão de luz sâo os responsáveis finais pelas esplêndidas cores observadas. [6] Além dos átomos excitados poderão também formarse outras espécies excitadas que emitam no vísivel; por exemplo o ião molecular $\mathrm{BaCl}$ - ou $\mathrm{SrCl}^{\text {; }}$, para os sais de bário ou estrôncio.

Nas condiçōes térmicas predominantes o sal de sódio emite uma luz amarelo-alaranjada, o de estrôncio uma luz vermelho-carmim e o de bário uma luz verde-ténue. Estes efeitos sẫo utilizados na caracterização espectroscópica dos elementos assim como na pirotecnia.

\section{Respostas às perguntas:}

1- Ver etimologia da palavra artificio; citaçāo do Leonardo: "Onde a natureza finda de produzir as suas espécies, começa o homem, em harmonia com as leis da natureza, a criar uma infinidade de espécies"; " "A psicanálise do fogo" de Gaston Bachelard.

2- Quando os cientistas fizeram passar a emissão de certos elementos através de um prisma, observaram a existência de linhas de cor intervaladas

com zonas negras; ou seja, o espectro de emissão não é continuo, é um espectro de linhas. Esta observação, assim como a própria existência da Tabela Periódica proposta por Mendeleev, não podiam ser explicadas com o modelo atómico (de Rutherford) aceite na época.

3. Um espectro é uma imagem que reflecte a estrutura electrónica; como cada elemento tem uma estrutura electrónica caracteristica, o seu espectro pode servir como uma impressão digital.

\section{Referências}

[1] F. R. KreißI, O. Krătz, "Feuer und Flamme, Schall und Rauch. Schauexperimente und Chemiehistorisches", Wiley-VCH, 1999, p. 99-104. [2] E. Wilson, Chem. Eng. News, 79 (2002), 30.

[3] P. Atkins, L. Jones "Chemistry, molecules, matter and change", $3^{\text {ra }} \mathrm{Ed}$, Freemand, 1997, cap. 7.

[4] S. Russo e M. Silver "Introductory Chemistry" Benjamin Cummings,

2.'ed., 2002. pp107-108 e 119-121; de salientar que os autores intitulam a primeira secçāo do capítulo dedicado ao moderno modelo do átomo, Seeing the light- a new model of the atom.

[5] H. W. Roesky, K. Möckel, "Chemical curiosities: spectacular experiments and inspired quotes", $\mathrm{VCH}, 1996, \mathrm{pp} 45-47$.

[6] K. Nassau, "Experimenting with color", Grolier Publishing, 1997, capitulo 6. 
0 vermelho, o branco e o azul dos fogos-de-artifício não são mais do que a luz emitida por átomos e moléculas energeticamente excitadas. O fenómeno responsável pela luz espectacular de um fogo-de-artificio está também na origem das cores observadas na iluminação das ruas, em muitos anúncios luminosos, ou ainda pela emissão amarelo-alaranjada, característica do sódio, que ocorre frequentemente nas nossas cozinhas sempre que alguns cristais de sal de cozinha caem na chama. Por acção da chama o cloreto de sódio (sal) é separado nos seus iōes, ficando o átomo de sódic com 1 electrão desemparelhado na última orbital. A elevada temperatura da chama vai permitir formar átomos de sódio no estado excitado. 0 átomo de sódio excitado perderá o seu excesso de energia em parte por emissão de calor em parte por emissão de luz. 0 actual modelo do átomo mostra que um electrão num átomo só pode existir numa série de estados discretos, denominados níveis de energia. Assim, o átomo de sódio só pode absorver e emitir energia de determinados valores, correspondentes à diferença entre esses niveis, ou seja, a energia dos electrōes de um átomo está quantificada. Deste modo a energia não é emitida ou absorvida num continuo, mas sim em intervalos determinados pela estrutura electrónica, e por esse motivo característicos, de cada átomo. A maior parte da energia que é libertada por um átomo de sódio excitado tem o valor de $3.38 \times 10^{19} \mathrm{~J}$, ou seja, um comprimento de onda igual a $589 \mathrm{~nm}$, o que corresponde a uma bela e intensa cor amarela. Os químicos podem pois utilizar este tipo de testes de chama para verificar/indagar se o sódio se encontra presente numa determinada amostra ou composto. E quem diz o sódio diz toda uma série de outros metais.

É a elevada temperatura de combustão que permite a fusāo e a queima de aparas de metal durante a detonação de um corpo de fogo-de-artificio e que dá origem aos processos químicos responsáveis pela cor. A cor observada deve-se à emissão de fotões quando ocorre transição dos electrões energeticamente excitados, de niveis de energia elevados para niveis de energia mais baixos, o que pode ocorrer tanto em átomos como em moléculas.

A história do fogo-de-artificio está, como não podia deixar de ser, ligada à história da química e alguns químicos famosos contribuíram ao longo dos tempos para que os fogos pudessem ser cada vez mais coloridos e espectaculares. A descoberta de compostos comburentes mais reactivos permitiu elevar as temperaturas atingidas durante a detonação dos fogos e a utilização de uma maior gama de compostos metálicos com elevadas temperaturas de combustão. Neste ponto as teorias de Lavoisier dos ácidos e os trabalhos de Berthollet foram essenciais, tendo levado à descoberta do clorato de potássio, utilizado nesta demonstraçāo. 0 entendimento dos fenómenos químicos que permitiram um maior controlo do brilho e da cor dos fogos-de-artifício está associado às teorias da constituição da matéria, nomeadamente à moderna Teoria do Átomo.
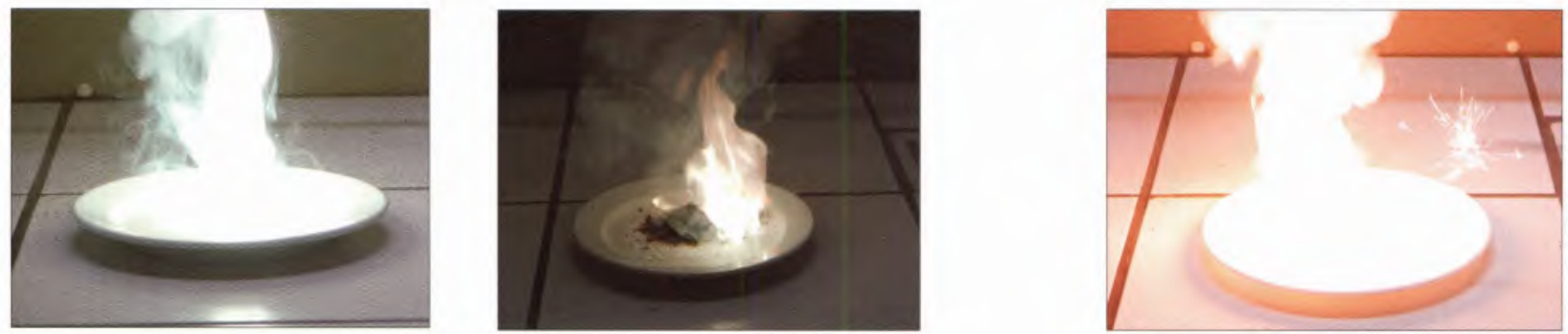

fogo verde; demonstração para o sal de bário no seu inicio e no final;

fogo amarelo, demonstração para o sal de sódio: (a chama emitida é de um belíssimo amarelo, no entanto é tão intensa que não foi possivel captar a cor).

\section{Experimente}

\section{Reagentes:}

\begin{tabular}{lll} 
Fogo Amarelo & Fogo Verde & Fogo Vermelho \\
\hline $4 \mathrm{~g} \mathrm{Cl}$. de Potássio & $4 \mathrm{~g} \mathrm{Cl}$. de Potássio & $4 \mathrm{~g} \mathrm{Cl}$. de Potássio \\
$\mathrm{KClO}_{3}$ & $\mathrm{KClO}_{3}$ & $\mathrm{KClO}_{3}$ \\
$4 \mathrm{~g} \mathrm{Nit.de} \mathrm{Sódio}$ & $6.2 \mathrm{~g} \mathrm{Nit.} \mathrm{de} \mathrm{Bário}$ & $5 \mathrm{~g} \mathrm{Nit}$ de Estrôncio \\
$\mathrm{NaNO}_{3}$ & $\mathbf{B a}\left(\mathrm{NO}_{3}\right)_{2}$ & $\mathrm{Sr}_{2}\left(\mathrm{NO}_{3}\right)_{2}$ \\
$5 \mathrm{~g} \mathrm{Açucar}^{5 \mathrm{~g} \mathrm{Açucar}}$ & $5 \mathrm{~g} \mathrm{Açucar}$ \\
\hline
\end{tabular}

\section{Segurança}

O clorato de potássio é comburente e tóxico, o nitrato de sódio e o nitrato de estrôncio são também comburentes, o nitrato de bário é tóxico. Esta demonstração só deve ser realizada por pessoas qualificadas! 0 uso de óculos de segurança e luvas é imprescindivel! A quantidade dos reagentes a utilizar deve ser ajustada à sala onde as experiências vão ser realizadas uma vez que durante a reacção exotérmica ocorre forte libertação de fumos. (Num laboratório de aulas pode realizar-se a experiência numa hotte).

Perigo de explosão: As substâncias nunca devem ser trituradas juntas no mesmo almofariz.

\section{Materiais:}

Almofariz, 3 copos de precipitaçāo de $1 \mathrm{~L}, 3$ recipientes resistentes ao calor (p.e. prato de cerâmica, ø aprox, $30 \mathrm{~cm}$ ), 1 Pena 1 estrela mágica (das utilizadas nos bolos de aniversário como foguete)

\section{Procedimento:}

O clorato de potássio, o açúcar e os diversos nitratos deverão ser finamente triturados, separadamente, num almofariz.

Antes da demonstração o clorato de potássio deve ser misturado com a correspondente mistura açúcar-nitrato. Para evitar perigo de explosão esta mistura deve ser feita muito cuidadosamente, num copo de cristalização, com uma pena ou por agitação ligeira do copo. A mistura é colocada num

recipiente resistente ao calor e a ignição é feita com uma estrela mágica, também conhecido nas pastelarias como foguete para bolos de aniversário.

\section{Eliminação de resíduos:}

Os resíduos do fogo devem ser colocados em água e tratados com carbonato de sódio. Após separação por sedimentação e decantação, os residuos sólidos deitam-se no lixo e a água pode ser despejada no esgoto normal.

\section{Para responder}

1. O nome "fogo-de-artifício" é poético e muito adequado ao fenómeno no desenvolvimento da moderna teoria atómica? observado. Comente. 